ARTICLE

\title{
Autocatalytic photoredox Chan-Lam coupling of free diaryl sulfoximines with arylboronic acids
}

Cong Wang ${ }^{1,6}$, Hui Zhang ${ }^{1,6}$, Lucille A. Wells ${ }^{2,6}$, Tian Liư ${ }^{3}$, Tingting Meng1, Qingchao Liu ${ }^{3}$, Patrick J. Walsh (D) ${ }^{2}$, Marisa C. Kozlowski id ${ }^{2 凶} \&$ Tiezheng Jia (i) ${ }^{1,4,5 凶}$

$\mathrm{N}$-Arylation of $\mathrm{NH}$-sulfoximines represents an appealing approach to access $\mathrm{N}$-aryl sulfoximines, but has not been successfully applied to $\mathrm{NH}$-diaryl sulfoximines. Herein, a coppercatalyzed photoredox dehydrogenative Chan-Lam coupling of free diaryl sulfoximines and arylboronic acids is described. This neutral and ligand-free coupling is initiated by ambient light-induced copper-catalyzed single-electron reduction of $\mathrm{NH}$-sulfoximines. This electron transfer route circumvents the sacrificial oxidant employed in traditional Chan-Lam coupling reactions, increasing the environmental friendliness of this process. Instead, dihydrogen gas forms as a byproduct of this reaction. Mechanistic investigations also reveal a unique autocatalysis process. The $\mathrm{C}-\mathrm{N}$ coupling products, $\mathrm{N}$-arylated sulfoximines, serve as ligands along with $\mathrm{NH}$-sulfoximine to bind to the copper species, generating the photocatalyst. DFT calculations reveal that both the $\mathrm{NH}$-sulfoximine substrate and the $\mathrm{N}$-aryl product can ligate the copper accounting for the observed autocatalysis. Two energetically viable stepwise pathways were located wherein the copper facilitates hydrogen atom abstraction from the $\mathrm{NH}$-sulfoximine and the ethanol solvent to produce dihydrogen. The protocol described herein represents an appealing alternative strategy to the classic oxidative Chan-Lam reaction, allowing greater substrate generality as well as the elimination of byproduct formation from oxidants.

\footnotetext{
${ }^{1}$ Shenzhen Grubbs Institute and Department of Chemistry, Southern University of Science and Technology, Shenzhen, Guangdong, China. ${ }^{2}$ Roy and Diana Vagelos Laboratories, Penn/Merck Laboratory for High-Throughput Experimentation, Department of Chemistry, University of Pennsylvania, Philadelphia, PA, USA. ${ }^{3}$ Department of Pharmaceutical Engineering, College of Chemical Engineering, Northwest University, Xi'an, Shanxi, China. ${ }^{4}$ State Key Laboratory of Elemento-Organic Chemistry, Nankai University, Tianjin, China. ${ }^{5}$ Guangdong Provincial Key Laboratory of Catalysis, Shenzhen, Guangdong, China. ${ }^{6}$ These

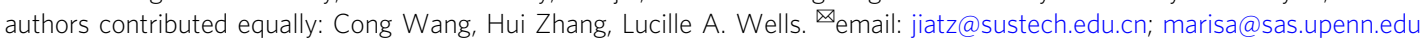


$\mathrm{N}$ ot long ago, sulfoximines were virtually unknown structural motifs in biological and medicinal chemistry ${ }^{1-5}$. This changed with Bayer's finding of the sulfoximinebased pan-CDK inhibitor (BAY 1000394, Fig. 1a) ${ }^{6}$. Since then, sulfoximines have received increasing attention as promising scaffolds and building-blocks in organic synthesis ${ }^{3,4}$ and as synthetic bioactive molecules in drug development (Fig. 1a) ${ }^{7,8}$. Sulfoximines also find widespread applications in agricultural chemistry, as exemplified by sulfoxaflor, a marketed insecticide ${ }^{9}$. Other uses of sulfoximines are as ligands in asymmetric catalysis ${ }^{4,10,11}$.

Considering the unique structural features of sulfoximines, and their successful applications in medicinal chemistry, much effort has been devoted to their preparation. Conventional approaches to sulfoximines involve oxidation of sulfilimines, oxidative imination of sulfoxides ${ }^{5}$, or direct sequential oxidation of sulfides to sulfoximines ${ }^{12,13}$. These methods require strong oxidizing agents and are less suitable for late stage modifications. Direct arylation of the nitrogen of $\mathrm{NH}$-sulfoximines represents an appealing and efficient approach to $N$-arylated sulfoximines ${ }^{14-17}$. The Buchwald-Hartwig amination was first applied to arylation of alkyl aryl $\mathrm{NH}$-sulfoximines by Bolm and co-workers (Fig. 1b) ${ }^{18}$. Surprisingly, general methods for the $\mathrm{N}$-arylation of diaryl $\mathrm{NH}$-sulfoximines, $\mathrm{Ar}_{2} \mathrm{SO}(\mathrm{NH})$, using the Buchwald-Hartwig approach have not been developed to date. This gap is attributed, in part, to the lower nucleophilicity of these species relative to alkyl substituted $\mathrm{NH}$-sulfoximines, (alkyl)ArSO(NH). The only successful examples of arylations of diaryl $\mathrm{NH}$-sulfoximines $\left[\mathrm{Ar}_{2} \mathrm{SO}(\mathrm{NH})\right]$ employed diaryliodonium salts (two examples) ${ }^{19}$ or aryl tosylates (three examples) ${ }^{20}$ as coupling partners. Although these advances are of significance, the scope they define is quite narrow and currently unsuitable for generating diversity.

The first systematic study of the arylation of diaryl $\mathrm{NH}$-sulfoximines was disclosed by the Yu group (Fig. 1b) ${ }^{21}$. Their optimal conditions employed $40 \mathrm{~mol} \% \mathrm{Cu}(\text { acac })_{2}$ and benzoyl peroxide at $130{ }^{\circ} \mathrm{C}$ to drive $\mathrm{N}$-arylation via a radical pathway. König and Wimmer and the team of Hog, Meier, and co-workers, described similar photoredox-catalyzed $N$-arylation of free sulfoximines with electron-rich arenes (Fig. 1b) ${ }^{22-24}$. Although elegantly circumventing the need for an electrophilic coupling partner, the application of this approach is hampered by limited substrate scope and regioselectivity issues arising from the reaction of highly reactive radical intermediates. Several scattered examples of $\mathrm{NH}$-diaryl sulfoximine $\mathrm{N}$-arylations were described by Bolm ${ }^{25}$ and other groups ${ }^{20,24,26,27}$. Unfortunately, low yields were generally observed. A direct and efficient $\mathrm{N}$-arylation protocol for $\mathrm{NH}$-diaryl sulfoximines with broad substrate scope, including heteroaryl coupling partners, is still an unmet need.

The copper-catalyzed Chan-Lam amination ${ }^{28,29}$ is one of the most powerful tools to construct $\mathrm{C}-\mathrm{N}$ bonds ${ }^{30}$, offering the advantages of (a) inexpensive copper-based catalysts that can often operate without added ligands, (b) mild reaction conditions, and (c) use of readily available boronic acids as coupling partners. Because the Chan-Lam amination is a coupling of two nucleophiles, an oxidant is required. Thus, a major drawback of ChanLam aminations arise from the oxidation of the substrates by the oxidant, including oxidative deboration of arylboronic acids to phenols ${ }^{31,32}$. In this regard, the discovery of a Chan-Lam coupling that does not require addition of an external oxidant would represent a significant advance.

The role of the oxidant in Chan-Lam couplings is generally believed to be to oxidize $\mathrm{Cu}(\mathrm{I})$ to $\mathrm{Cu}(\mathrm{II})^{31,33}$, although it has also been postulated that it oxidizes $\mathrm{Cu}$ (II) to $\mathrm{Cu}(\mathrm{III})^{26}$. Inspired by the pioneering work of Fu, Peters, and their co-workers on the photoinduced Ullmann coupling ${ }^{34,35}$ and related $C\left(s p^{3}\right)-N$ bond constructions ${ }^{36-39}$, we hypothesized that the photo-induced singleelectron oxidation of the catalysts from $\mathrm{Cu}$ (I) to $\mathrm{Cu}$ (II) could serve as an alternative to external oxidants, allowing the development of a photoredox Chan-Lam coupling protocol without external oxidants. Of note, Kobayashi and co-workers ${ }^{40}$ reported a visible-lightmediated Chan-Lam coupling of arylboronic acids with aniline derivatives. This study, which employed an Ir-photocatalyst with dioxygen as the terminal oxidant, demonstrated the compatibility of Chan-Lam amination with photoredox conditions.

Another source of inspiration came from the Bolm group, who developed a copper-catalyzed Chan-Lam amination of

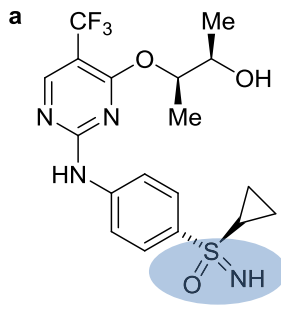

BAY 1000394

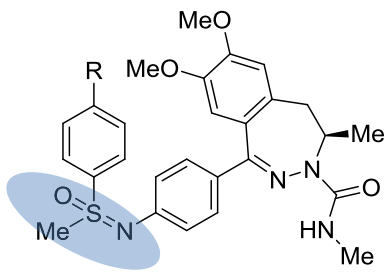

BET Protein Inhibitor derivative BRD4 Inhibitor

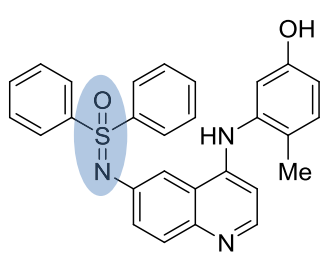

EphB4 Receptor Inhibitor

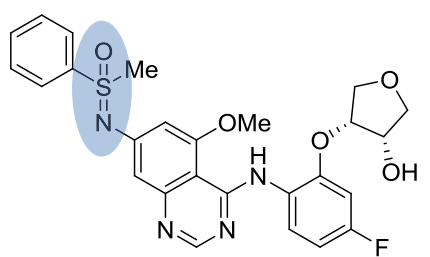

MNK Kinase Inhibitor derivative

b

$$
\begin{aligned}
& \text { Bolm (1998) }
\end{aligned}
$$

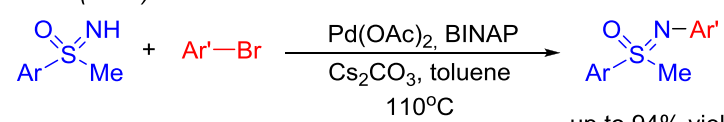

Yu (2016)

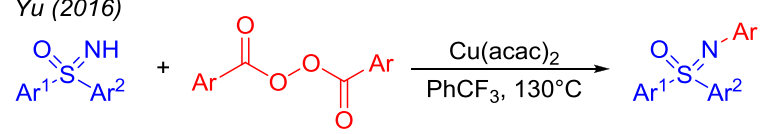

König (2018)
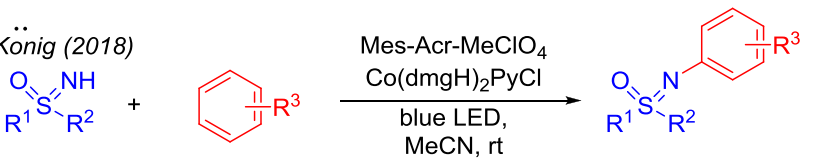

c

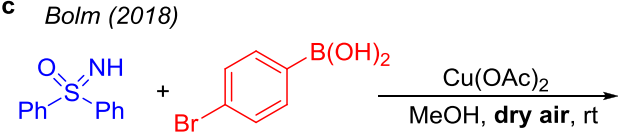

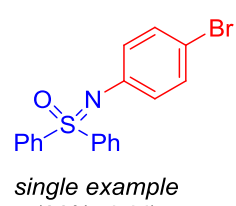

(26\% yield)

d This work

$$
\mathrm{Ar}^{1}{ }^{-\mathrm{S}^{\prime \prime}} \mathrm{Ar}^{2}+\mathrm{Ar}^{3} \mathrm{~B}(\mathrm{OH})_{2}
$$

$\mathrm{Cu}\left(\mathrm{O}_{2} \mathrm{CCF}_{3}\right)_{2} \cdot \mathrm{H}_{2} \mathrm{O}$ $\mathrm{EtOH}$, sunlight, rt external oxidant-free

Fig. $1 \mathbf{N}$-Arylation of sulfoximines. a Representative examples of bioactive sulfoximines. b Three reported strategies to $N$-aryl sulfoximines. c $N$-arylation of diaryl sulfoximine via traditional Chan-Lam reaction. d This photoredox Chan-Lam Coupling of free diaryl sulfoximines with arylboronic acids. 
$\mathrm{NH}$-dialkyl- and $\mathrm{NH}$-arylalkyl sulfoximines with arylboronic acids employing oxygen in dry air as the oxidant ${ }^{14,25}$. Their single example of an $\mathrm{N}$-arylation employing 4-bromophenylboronic acid and $N H$-diphenyl sulfoximine (26\% yield, Fig. 1c) attracted our attention. Herein, we report the development of a general and straightforward light-induced copper-catalyzed Chan-Lam arylation of free diaryl sulfoximines with arylboronic acids (Fig. 1d). Notable features of this protocol include: (a) a variety of functional groups are well tolerated, including heteroarylboronic acids and heteroaryl-containing sulfoximines; (b) no external oxidant is required, eliminating oxidant-based byproduct formation; (c) an inexpensive copper source serves as photocatalyst; (d) mechanistic studies reveal an autocatalysis process, arising from ligation of $\mathrm{N}$-aryl sulfoximines to copper(I) species; and (e) dihydrogen is the byproduct in this coupling, which is simply purged from the reaction vessel.

\section{Results and discussion}

Reaction discovery and optimization. Our goal was to develop a Chan-Lam coupling that did not require external oxidant. We initiated the optimization of copper-catalyzed $\mathrm{N}$-arylation of $\mathrm{NH}$ diphenyl sulfoximine 1a (1.0 equiv) with phenylboronic acid 2a (2.3 equiv) in methanol $(0.3 \mathrm{M})$ for $48 \mathrm{~h}$ with catalytic $\mathrm{Cu}\left(\mathrm{O}_{2} \mathrm{CCF}_{3}\right)_{2} \cdot \mathrm{H}_{2} \mathrm{O}(20 \mathrm{~mol} \%)$, similar to the conditions reported by Bolm and co-workers ${ }^{25}$ (Fig. 1c). Rather than conducting the reaction under oxidizing conditions, however, it was performed under an argon atmosphere to exclude the sacrificial oxidant $\left(\mathrm{O}_{2}\right.$ in air). We observed formation of the desired product in $25 \% \mathrm{AY}$ of 3aa ( $\mathrm{AY}=$ assay yield, Table 1, entry 1 ). After a survey of copper sources, $\mathrm{Cu}\left(\mathrm{O}_{2} \mathrm{CCF}_{3}\right)_{2} \cdot \mathrm{H}_{2} \mathrm{O}$ was determined to be the best among those examined, giving $36 \% \mathrm{AY}$ of $\mathbf{3 a a}$ (entry 4 vs. entries $1-3$, Table 1$)$. We next examined $\mathrm{Cu}\left(\mathrm{O}_{2} \mathrm{CCF}_{3}\right)_{2} \cdot \mathrm{H}_{2} \mathrm{O}$ in commonly used alcohol solvents $(\mathrm{EtOH}, \mathrm{irOH}$, and $t \mathrm{BuOH}$, entries 5-7, Table 1). When EtOH was employed, 3aa was afforded in $90 \% \mathrm{AY}$ (entry 5 , Table 1 ). We next examined the catalyst loading and found that decreasing to $10 \mathrm{~mol} \% \mathrm{Cu}\left(\mathrm{O}_{2} \mathrm{CCF}_{3}\right)_{2} \cdot \mathrm{H}_{2} \mathrm{O}$, provided $90 \%$ AY of $3 \mathbf{a a}$ (entry 8 , Table 1). Other reaction parameters, such as reagent ratio and concentration, were next examined. The stoichiometry of boronic acid $\mathbf{2 a}$ could be decreased from 2.3 to 2.0 equiv, without impacting the AY (90\%, entry 10 , Table 1$)$. Interestingly, the concentration could be increased from 0.3 to 1.5 M, generating 3aa in 95\% AY (entry 12, Table 1) and 94\% isolated yield. No coupling product formed in the absence of $\mathrm{Cu}$ $\left(\mathrm{O}_{2} \mathrm{CCF}_{3}\right)_{2} \cdot \mathrm{H}_{2} \mathrm{O}$, confirming that the copper acted as catalyst. Therefore, the optimized conditions for the $\mathrm{N}$-arylation were determined to be: sulfoximine $\mathbf{1 a}$ as limiting reagent, boronic acid 2a (2.0 equiv), $\mathrm{Cu}\left(\mathrm{O}_{2} \mathrm{CCF}_{3}\right)_{2} \cdot \mathrm{H}_{2} \mathrm{O}(10 \mathrm{~mol} \%)$ as catalyst, in ethanol $(1.5 \mathrm{M})$ at room temperature for $48 \mathrm{~h}$. Other boronic acid equivalents were also explored. The pinacol ester of phenylboronic acid led to poor yield of $\mathbf{3 a a}$, presumably owing to inhibition of the copper by coordination to pinacol (entry 15, Table 1$)^{31}$. Furthermore, the employment of three equiv $\mathrm{B}(\mathrm{OH})_{3}$ as additive ${ }^{31}$ exerted negligible effect on the outcome of the transformation, and only $20 \%$ yield of $\mathbf{3 a a}$ was obtained (entry 15 , Table 1 ). Phenyl trifluoroborate was only effective in forming $\mathbf{3 a a}$ at reduced levels (entry 16, Table 1).

Substrate scope. With the optimized conditions in hand (Table 1, entry 12), we investigated the substrate scope of the arylboronic acids in the copper-catalyzed arylation of $\mathbf{1 a}$ (Table 2). Boronic acids bearing electron-donating $4-\mathrm{Me}$ and 4 -OMe groups $(\mathbf{2 b}, \mathbf{2 c})$ produced the corresponding arylated sulfoximines $\mathbf{3} \mathbf{a b}$ and $\mathbf{3 a c}$ in $96 \%$ and $85 \%$ yield, respectively. Halogenated arylboronic acids containing 4-F (2d), 4-Cl (2e) or 4- $\mathrm{Br}$ (2f) substitution reacted smoothly, generating 3ad-f in $83-91 \%$ yield. Sterically hindered 1-naphthylboronic acid (2g) afforded $75 \%$ yield $3 a g$ with $15 \mathrm{~mol}$ \% copper catalyst. 3,5-Dimethylphenylboronic acid (2h) also proved to be a good coupling partner, and $\mathbf{3 a h}$ was obtained in $80 \%$ yield. The chemistry was also accommodated by arylboronic acids possessing strongly electron-withdrawing groups to furnish 3ai-3ak in yields ranging from $59 \%$ to $82 \%$.

The oxidant-free conditions enabled use of a broad range of functional groups on the arylboronic acids, including aldehyde (21), methyl ketone (2m), methyle ester (2n), and even free hydroxyl (2o) groups $(60-80 \%)$. The coupling of the unprotected phenol is particularly impressive, because phenols are well known to couple in Chan-Lam reactions to give diaryl ethers ${ }^{27}$. Heterocyclic sulfoximines exhibit a broad range of biological activities and, thus, are important synthetic targets. To our delight, 3-pyridinyl (2p), 3-thiophenyl (2q), and 5-NH-indolyl (2r) boronic acid derivatives furnished the corresponding products $3 \mathbf{p}-\mathbf{r}$ in $65-75 \%$. Of note, our arylation displayed excellent chemoselectivity favoring arylation of the sulfoximine 3ar over arylation of the indole $\mathrm{N}-\mathrm{H}$. In a preliminary probe, vinylboronic acid failed to form the desired product under the standard conditions.

Next, the substrate generality of $\mathrm{NH}$-diaryl sulfoximines was investigated using phenylboronic acid (2a) (Table 2). Phenyl and electron-donating 4-Me (1b) and 4-OMe (1c) $3,5-\mathrm{Me}$ (1d) substituted sulfoximines reacted smoothly with 2a to furnish 3aa-3da in $75-95 \%$ yield. The sulfoximine possessing a 4-NHAc group (1e) furnished the product 3ea yield 63\% with no observed $\mathrm{N}$-arylation of the amide. $\mathrm{NH}$-Sulfoximines possessing halogens and electron-withdrawing functionality, such as $4-\mathrm{F}$ (1f), 4-Cl $(\mathbf{l g}), 4-\mathrm{CN}(\mathbf{l h}), 4-\mathrm{CF}_{3}(\mathbf{l i}), 4-\mathrm{NO}_{2}(\mathbf{1 j})$ or $4-\mathrm{CO}_{2} \mathrm{Me}(\mathbf{1 k})$ groups, proved to be compatible coupling partners, providing $3 \mathbf{f a}-\mathbf{3 k a}$ in $71-92 \%$ yields. A free sulfoximine bearing $4-\mathrm{COMe}$ (11) provided the arylation product 31 a in $80 \%$ yield. Furthermore, unprotected 4- $\mathrm{COOH}(\mathbf{1} \mathbf{m})$ and 3-OH (1n) appended phenyl sulfoximines proceeded smoothly under the optimized conditions to provide 3ma and 3na in $88 \%$ and $82 \%$, respectively. These results highlight the excellent chemoselectivity of our protocol, favoring $\mathrm{C}-\mathrm{N}$ bond coupling over C-O bond formation. Sterically hindered 1-naphthyl phenyl sulfoximine 10 required an extended reaction time $(60 \mathrm{~h})$, but furnished coupling product $3 \mathbf{3 o a}$ in $70 \%$ yield. Notably, heterocyclic 2-pyridyl (1p) and 3-thiophenyl sulfoximines (1q) were also suitable substrates, affording $\mathbf{3 p a}$ and $\mathbf{3 q a}$ in $65 \%$ and $73 \%$ yield, respectively.

To demonstrate the utility of our copper-catalyzed $\mathrm{N}$-arylation protocol, the bis- $\mathrm{NH}$-sulfoximine (1r) furnished the bis-arylation product 3ra in 56\% yield (Table 2). It is noteworthy that bissulfoximine 3ra could be utilized as a ligand for transition-metal catalysis, as evidenced by its structural similarity to known bissulfoxide ligands ${ }^{11}$. $\mathrm{N}$-Heteroaryl-diheteroaryl sulfoximines are a class of compounds that have been challenging to prepare, as judged by the lack of examples in the literature. Our method enabled the preparation of one such member of this class in $42 \%$ yield (3sm, Table 2).

Mechanistic studies. We performed a series of experiments to gain insight into the reaction mechanism. Following our hypothesis of photoredox $\mathrm{C}-\mathrm{N}$ coupling, the impact of light on the reaction was explored. When the standard reaction of $1 \mathbf{a}$ and 2a was performed in the dark, 3aa was only obtained in $8 \%$ yield after $48 \mathrm{~h}$ (Fig. 2a), indicating the pivotal role of ambient light on the conversion. To test whether the reaction proceeds via a radical pathway or a $\mathrm{Cu}-\mathrm{H}$ intermediate, addition of one equiv of 2,2,6,6tetramethylpiperidine-1-oxyl (TEMPO) to the reaction of 1 a with 2a was performed. TEMPO-H (4) was observed in $10 \%$ yield, along with $16 \%$ 3aa (Fig. 2b). Likewise, the introduction of 
Table 1 Optimization of copper-catalyzed photoredox Chan-Lam coupling of 1a with $2 a$.

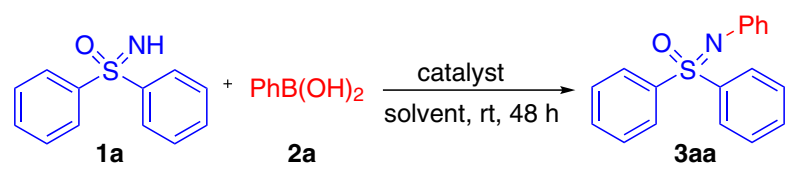

\begin{tabular}{|c|c|c|c|c|}
\hline Entry & catalyst/mol \% & Solvent & Conc./M & Assay yielda $/ \%$ \\
\hline 1 & $\mathrm{Cu}(\mathrm{OAc})_{2} \cdot \mathrm{H}_{2} \mathrm{O} / 2 \mathrm{O}$ & $\mathrm{MeOH}$ & 0.3 & 25 \\
\hline 3 & $\mathrm{CuF}_{2} / 20$ & $\mathrm{MeOH}$ & 0.3 & 30 \\
\hline 5 & $\mathrm{Cu}\left(\mathrm{O}_{2} \mathrm{CCF}_{3}\right)_{2} \cdot \mathrm{H}_{2} \mathrm{O} / 2 \mathrm{O}$ & $\mathrm{EtOH}$ & 0.3 & 90 \\
\hline 6 & $\mathrm{Cu}\left(\mathrm{O}_{2} \mathrm{CCF}_{3}\right)_{2} \cdot \mathrm{H}_{2} \mathrm{O} / 2 \mathrm{O}$ & iPrOH & 0.3 & 49 \\
\hline 7 & $\mathrm{Cu}\left(\mathrm{O}_{2} \mathrm{CCF}_{3}\right)_{2} \cdot \mathrm{H}_{2} \mathrm{O} / 2 \mathrm{O}$ & $\mathrm{tBuOH}$ & 0.3 & 0 \\
\hline $10^{b}$ & $\mathrm{Cu}\left(\mathrm{O}_{2} \mathrm{CCF}_{3}\right)_{2} \cdot \mathrm{H}_{2} \mathrm{O} / 10$ & $\mathrm{EtOH}$ & 0.3 & 90 \\
\hline $11^{c}$ & $\mathrm{Cu}\left(\mathrm{O}_{2} \mathrm{CCF}_{3}\right)_{2} \cdot \mathrm{H}_{2} \mathrm{O} / 10$ & $\mathrm{EtOH}$ & 0.3 & 75 \\
\hline $12^{b}$ & $\mathrm{Cu}\left(\mathrm{O}_{2} \mathrm{CCF}_{3}\right)_{2} \cdot \mathrm{H}_{2} \mathrm{O} / 10$ & $\mathrm{EtOH}$ & 1.5 & $95\left(94^{d}\right)$ \\
\hline $13^{b}$ & $\mathrm{Cu}\left(\mathrm{O}_{2} \mathrm{CCF}_{3}\right)_{2} \cdot \mathrm{H}_{2} \mathrm{O} / 10$ & $\mathrm{EtOH}$ & 2.0 & 85 \\
\hline $14^{b}$ & - & $\mathrm{EtOH}$ & 1.5 & 0 \\
\hline $15^{e}$ & $\mathrm{Cu}\left(\mathrm{O}_{2} \mathrm{CCF}_{3}\right)_{2} \cdot \mathrm{H}_{2} \mathrm{O} / 10$ & $\mathrm{EtOH}$ & 1.5 & $17\left(20^{f}\right)$ \\
\hline $16^{g}$ & $\mathrm{Cu}\left(\mathrm{O}_{2} \mathrm{CCF}_{3}\right)_{2} \cdot \mathrm{H}_{2} \mathrm{O} / 10$ & $\mathrm{EtOH}$ & 1.5 & 66 \\
\hline
\end{tabular}

General conditions: unless otherwise stated, reactions were carried out with $\mathbf{1 a}(0.3 \mathrm{mmol})$ and $\mathbf{2 a}(2.3$ equiv) at room temperature under argon for $48 \mathrm{~h}$

assay yields determined by ${ }^{1} \mathrm{H}$ NMR using $0.1 \mathrm{mmol} \mathrm{CH}_{2} \mathrm{Br}_{2}(7.0 \mu \mathrm{L})$ as internal standard.

b2a (2.0 equiv).

'2a ( 1.5 equiv).

disolated yield.

Phenyl boronic acid pinacol ester employed.

$\mathrm{B}(\mathrm{OH})_{3}$ (3.0 equiv) as an additive.

gPotassium phenyl trifluoroborate (3.0 equiv) employed for $72 \mathrm{~h}$.

1.0 equiv of 5,5-dimethyl-1-pyrroline $N$-oxide (DMPO) under otherwise standard reaction conditions with $1 \mathbf{a}$ and $\mathbf{2 a}$ resulted in the isolation of radical trapped complex 5. No 3aa was observed in the presence of DMPO (Fig. 2c). The HAT product 5 was confirmed by both electron paramagnetic resonance (Supplementary Fig. 1) and high-resolution mass spectrometry (HRMS) analysis (Supplementary Fig. 2).

As hydrogen radicals and copper hydrides have been proposed in copper-catalyzed hydrogen evolution reactions ${ }^{41-45}$, we hypothesized that the byproduct of our reaction might be dihydrogen. Examination of the reaction headspace by gas chromatography (GC) confirmed the formation of hydrogen gas (Supplementary Fig. 3).

A light on/off experiment was performed (Fig. 2d) to further explore the impact of irradiation with ambient fluorescent lights on reaction conversion. This experiment indicates that the copper-catalyzed Chan-Lam coupling indeed is a photoredoxcatalyzed process rather than a radical-chain pathway. Upon plotting the data, we were surprised to find an unusual increase in the rate of conversion during the second "light-on" period (24-36 h, Fig. 2d), which inspired us to further probe this phenomenon.

To explore the reaction time course, the copper-catalyzed photoredox Chan-Lam coupling was followed under constant ambient light exposure (Fig. 3a). At the initial stage of the reaction $(0-12 \mathrm{~h})$, the conversion to 3 aa increased slowly and reached only $11 \%$. The reaction entered a dormant stage (12-32 h), during which very little additional 3aa was generated (conversion increased from $11 \%$ to $15 \%$ ). Starting after $32 \mathrm{~h}$, the reaction entered an acceleration stage, and conversion to 3aa jumped to $89 \%$ within $10 \mathrm{~h}$. With the consumption of reactants 1a and 2a nearly complete, production of 3aa slowed, eventually reaching 95\% after $48 \mathrm{~h}$. We hypothesized that the acceleration phase might be owing to photoredox autocatalysis $46-48$, wherein the product of the reaction becomes the catalyst. This possibility was subsequently explored.

As sulfoximines have been widely utilized as ligands for transition-metal catalysis ${ }^{4,10,11}$, we speculated that the autocatalysis might arise from the in situ formation of a copper complex ligated by the $N$-arylated sulfoximine product. To test this hypothesis, we spiked the reaction mixture of $\mathbf{1 a}$ and $2 \mathbf{2}$ with product 3 aa and monitored the conversion under otherwise standard conditions. When the reaction mixtures were spiked with $20 \mathrm{~mol} \% 3$ aa and the reaction time course followed, $1 \mathbf{a}$ and 2a were steadily consumed over $40 \mathrm{~h}$ and 3aa was produced (Fig. 3b). Initiation of the reaction in the presence of $33 \mathrm{~mol} \%$ 3aa led to increased acceleration in the conversion of $\mathbf{1 a}$ and $\mathbf{2 a}$ to the product in under $10 \mathrm{~h}$. These results are consistent with autocatalysis by $\mathbf{3 a a}$.

We next examined the reaction mixtures by HRMS $^{31,49}$ with the goal of detecting intermediates in the transformation of 1a and 2a to 3aa. During the first stage of the reaction $(0-12 \mathrm{~h})$, copper(I) ligated with two $\mathrm{NH}$-sulfoximines 1a (complex A) was the major copper species detected by HRMS (Supplementary Fig. $4 \mathrm{a}-\mathrm{b}$ ). As the reaction progressed under argon and 3aa was generated, ligand exchange was observed by HRMS to generate a copper complex bound to two equiv 3aa (complex B) (Supplementary Fig. 4c-g).

To probe the role of $\mathbf{3 a a}$ as ligand for the copper-photocatalyst in the photoredox Chan-Lam coupling, arylation of methyl phenyl $\mathrm{NH}$-sulfoximine (6) with phenylboronic acid (2a) was investigated in the presence of $20 \mathrm{~mol} \%$ 3aa (Supplementary Table 1). Under otherwise standard conditions, $80 \%$ yield of $N$ arylated product 7 was obtained. In sharp contrast, the yield of 7 
Table 2 Substrate scope of copper-catalyzed photoredox Chan-Lam coupling.

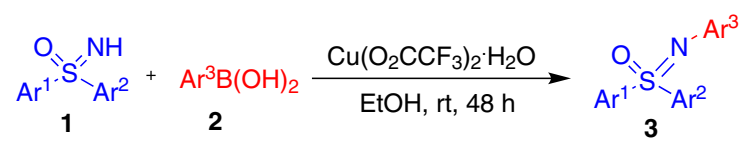

arylboronic acids scope<smiles>COc1ccc(N=S(=O)(c2ccccc2)c2ccccc2)cc1</smiles>

3ab, $96 \%$

3ac, $85 \%^{a}$<smiles>O=[SH](=NC(=Nc1ccc(F)cc1)c1ccccc1)c1ccccc1</smiles>

3ad, $83 \%$<smiles>O=S(=Nc1ccc(Cl)cc1)(c1ccccc1)c1ccccc1</smiles>

3ae, $91 \%$<smiles>O=S(=NCc1ccc(Br)cc1)(c1ccccc1)c1ccccc1</smiles>

3af, $90 \%$<smiles></smiles><smiles></smiles>

3ag, $75 \%^{\mathrm{b}}$<smiles>C/C=C/C=C/c1ccc(S(=O)(=Nc2ccc(C#N)cc2)c2ccccc2)cc1</smiles>

3ah, $80 \%^{a}$

3ai, $59 \%$<smiles></smiles>

3aj, $82 \%$

3ak, $66 \%$<smiles>C/C=C\C=N/S(=O)(=O)c1ccccc1</smiles>

3al, $80 \%$

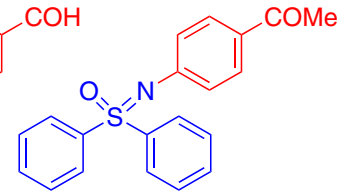

3am, $78 \%$<smiles>COC(=O)c1ccc(N=S(=O)(c2ccccc2)c2ccccc2)cc1</smiles>

3an, $60 \%$

3ao, $70 \%{ }^{\mathrm{b}}$

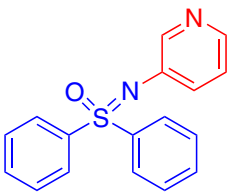<smiles>O=S(=Nc1ccsc1)(c1ccccc1)c1ccccc1</smiles><smiles></smiles><smiles>O=S(=Nc1ccccc1)(c1ccccc1)c1ccccc1</smiles>

3ap, $75 \%$

3aq, $65 \%$

3 ar, $65 \%^{\mathrm{b}}$

3aa, $95 \%$

free diaryl sulfoximines scope

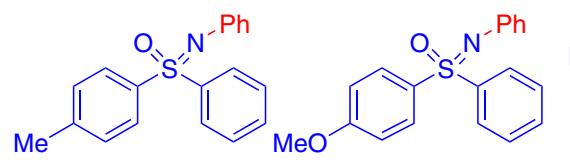

3ba, $95 \%$

3ca, $76 \%$<smiles>Cc1cc(C)cc(S(=O)(=Nc2ccccc2)c2ccccc2)c1</smiles>

3da, $75 \%$

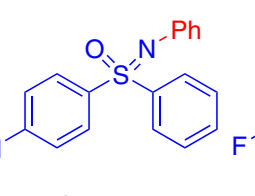

3ea, $63 \%$

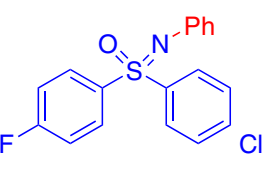

3fa, $80 \%$<smiles>O=S(=Nc1ccccc1)(c1ccccc1)c1ccc(I)cc1</smiles>

3ga, $89 \%$

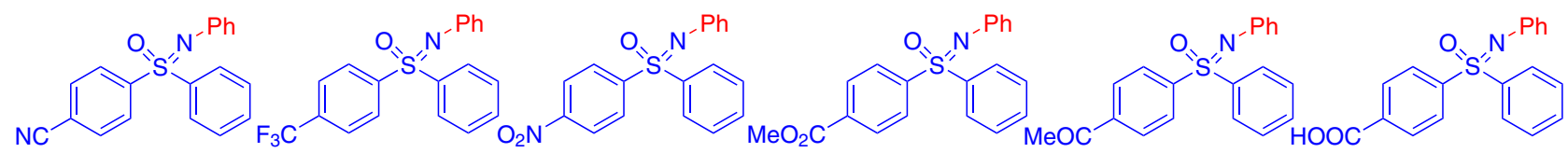

3ha, $71 \%$

3ia, $78 \%$

3ja, $89 \%$

3ka, $92 \%$

3la, $80 \%$

$3 \mathrm{ma}, 88 \%^{\mathrm{d}}$<smiles>O=S(=Nc1ccccc1)(c1ccccc1)c1cccc(O)c1</smiles>

3na, $82 \%$

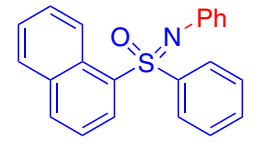

3oa, $70 \%$<smiles>O=S(=Nc1ccccc1)(c1ccccc1)c1ccccn1</smiles>

3pa, $65 \%^{\circledR}$

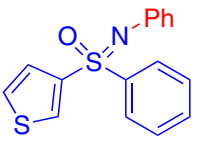

3qa, $73 \%{ }^{\mathrm{e}}$

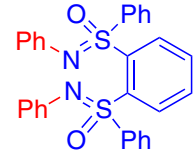

3ra, $56 \%$ single diastereomer

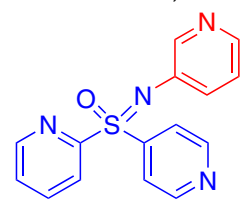

3sm, 42\%, $\mathrm{f}$

Reaction conditions: $1(0.75 \mathrm{mmol}), \mathbf{2}(1.5 \mathrm{mmol})$, and $\mathrm{Cu}\left(\mathrm{O}_{2} \mathrm{CCF}_{3}\right)_{2} \cdot \mathrm{H}_{2} \mathrm{O}(10 \mathrm{~mol} \%)$ in EtOH $(0.5 \mathrm{~mL})$ at room temperature under argon for $48 \mathrm{~h}$

a2 $(2.25 \mathrm{mmol})$.

${ }^{b} \mathrm{Cu}\left(\mathrm{O}_{2} \mathrm{CCF}_{3}\right)_{2} \cdot \mathrm{H}_{2} \mathrm{O}(15 \mathrm{~mol} \%)$

$\mathrm{C}^{2} \mathrm{~h}$.

dEtOH $(0.5 \mathrm{M}), 72 \mathrm{~h}$

e $60 \mathrm{~h}$

${ }^{\mathrm{E}} \mathrm{EtOH}(0.3 \mathrm{M})$ 
a) Reaction in Dark

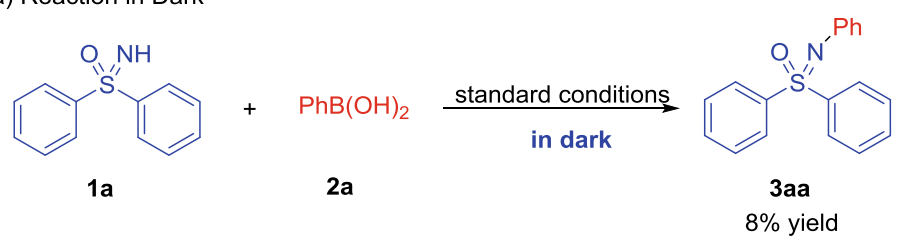

b) Catalytic Reaction with TEMPO<smiles>NS(=O)(=O)c1ccccc1</smiles>

$1 a$
$\mathrm{PhB}(\mathrm{OH})_{2}$

$2 a$

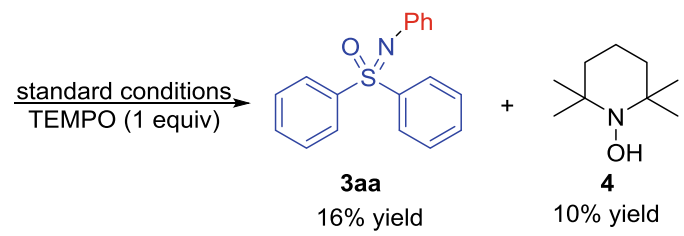

c) Spin Trap with DMPO<smiles>NS(=O)(=O)c1ccccc1</smiles>

1a<smiles>CC1(C)C=[N+]([O-])CC1</smiles><smiles></smiles>

3aa not detected
$+$

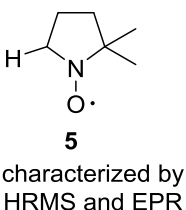

d) Light on/off experiment

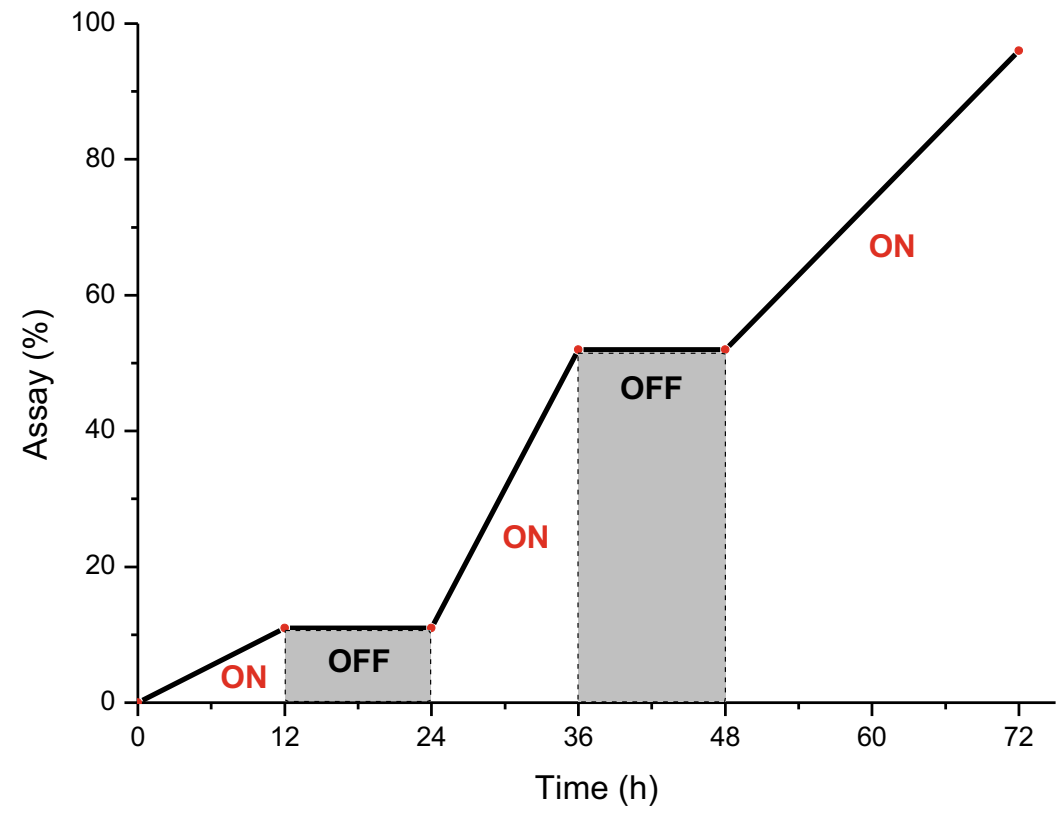

Fig. 2 Mechanistic probes. a Examination of the role of ambient light. b Probing the radical pathway of copper-catalyzed Chan-Lam coupling. c Spin trapping experiments. $\mathbf{d}$ Light on/off experiment with copper-catalyzed Chan-Lam coupling reaction of $\mathbf{1 a}$ and $\mathbf{2 a}$.

was only $7 \%$ if $\mathbf{3 a a}$ was not present (Supplementary Table 1). The marked difference in arylation yields clearly demonstrates that only $\mathrm{N}$-arylated, and not the $\mathrm{NH}$-diaryl sulfoximines-ligated copper complexes serve as competent catalyst for this photoredox Chan-Lam coupling.

Spectroscopic studies on the catalyst species were next performed. UV-Vis spectra of $\mathbf{1 a}, \mathbf{2 a}, \mathbf{3 a a}$, and $\mathrm{Cu}\left(\mathrm{NCCH}_{3}\right)_{4} \mathrm{PF}_{6}$ were recorded (Fig. 4a). As expected, these species do not exhibit appreciable absorption above $245 \mathrm{~nm}$. In contrast, independently synthesized copper(I) hexafluorophosphate complexes $[\mathrm{Cu}(\mathrm{N}(\mathrm{H})$ $\left.\left.\mathrm{OSPh}_{2}\right)_{2}\right]\left[\mathrm{PF}_{6}\right]\left(\mathbf{A}^{\prime}\right)$ and $\left[\mathrm{Cu}\left(\mathrm{N}(\mathrm{Ph}) \mathrm{OSPh}_{2}\right)_{2}\right]\left[\mathrm{PF}_{6}\right]$ B' (Supplementary Fig. 5) each exhibited a strong absorption that tails into the visible (Fig. $4 \mathrm{a}$ ). In addition, emission and excitation spectra of $\mathbf{A}^{\prime}$ and $\mathbf{B}$ ' confirmed that they exhibit very similar accessible excitations in the near-ultraviolet region (Supplementary Fig. 6). When the reaction mixture of $1 \mathbf{a}$ and $2 \mathbf{a}(0.5 \mathrm{M})$ was monitored, the max absorption was $\sim 782 \mathrm{~nm}$, which is indicative of a copper (II) species as the catalyst resting state (Fig. 4a).

A series of Stern-Volmer experiments of complex B' utilizing 1a, $\mathrm{EtOH}$, or $\mathbf{2 a}$ as additive were performed (Supplementary Fig. 7b). The results clearly show that sulfoximine la could effectively quench the excited copper(I) complex B' (Fig. 4b). In sharp contrast, solvent ethanol and $\mathbf{2 a}$ exerted negligible quenching effect on excited B' (Supplementary Fig. 7b). Similar quenching studies with complex $\mathbf{A}^{\prime}$ were also conducted, but surprisingly excited A' was not quenched by 1a (Fig. 4b), EtOH, or 2a (Supplementary Fig. 7a). This unexpected result excludes the possibility of $\mathbf{A}^{\prime}$ acting as a competent photocatalyst in this 

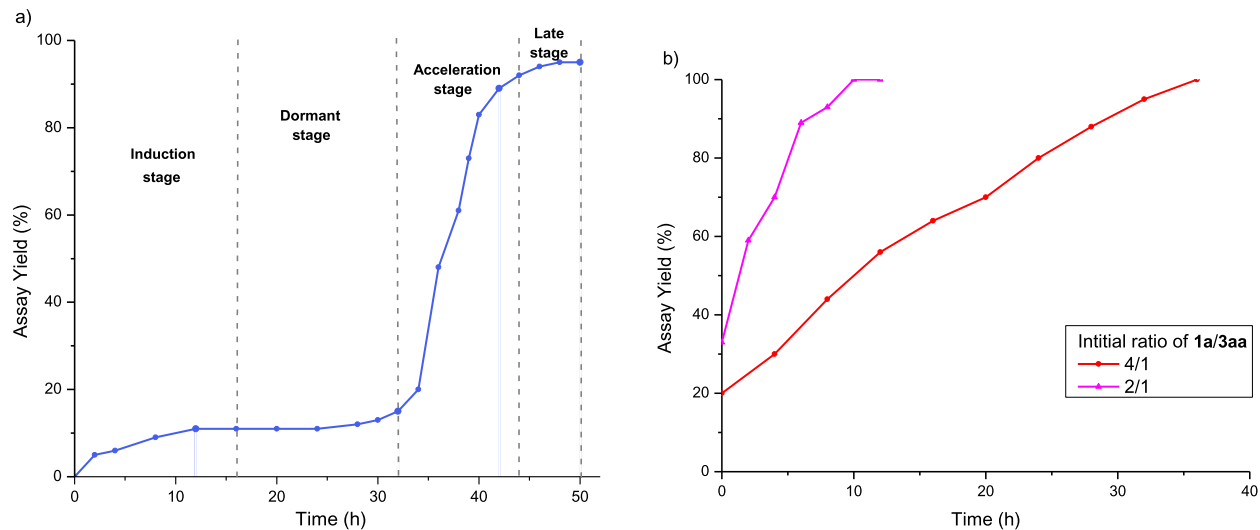

Fig. 3 Reaction profiles of copper-catalyzed photoredox Chan-Lam couplings. a Standard conditions. $\mathbf{b}$ Initiation in the presence of $3 a a$.
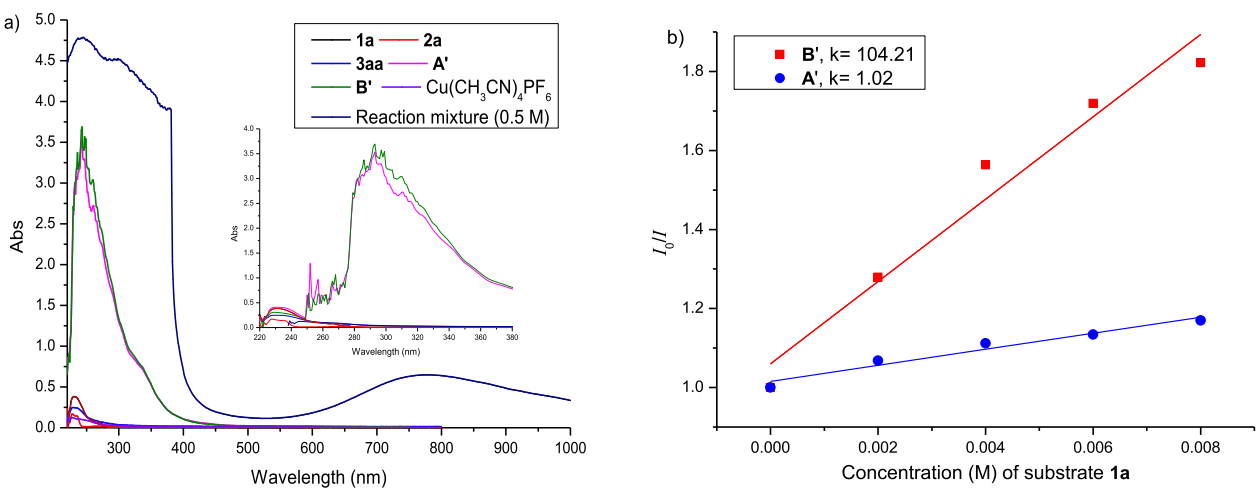

Fig. 4 Spectroscopic studies. a UV-Vis spectra of $\mathbf{1 a}, \mathbf{2 a}$, 3aa, $\mathbf{A}^{\prime}, \mathbf{B}^{\prime}$ and $\mathrm{Cu}\left(\mathrm{NCCH}_{3}\right)_{4} \mathrm{PF}_{6}$ in $\mathrm{DCM}\left(5 \times 10^{-5} \mathrm{M}\right)$ and reaction mixture in EtOH $(\mathbf{1} \mathbf{a}, 0.5 \mathrm{M})$. b, Stern-Volmer quenching efficiency of $\mathbf{1 a}$ with $\mathbf{A}^{\prime}$ and $\mathbf{B}^{\prime}\left(5 \times 10^{-5} \mathrm{M}\right.$ in $\left.\mathrm{DCM}, \lambda_{\mathrm{ex}}=344 \mathrm{~nm}\right)$.

Chan-Lam coupling. Simple copper(I) species $\mathrm{Cu}\left(\mathrm{NCCH}_{3}\right)_{4} \mathrm{PF}_{6}$ did not exhibit emission quenching when treated with the above additives either (Supplementary Fig. 7c). Taken together, these data allow us to propose that the autocatalysis phenomenon is owing to ligation of the $\mathrm{N}$-arylated sulfoximines 3 to copper(I) species.

Based on the results above and reports in the literature, a preliminary reaction pathway is proposed (Fig. 5). During the initial stoichiometric stage, a copper(II)-mediated $\mathrm{C}-\mathrm{N}$ coupling occurs between free sulfoximine (1) and arylboronic acid (2) to give a small amount of $\mathrm{N}$-aryl sulfoximine (3) (induction period, Fig. 3a). Here, a transmetallation between [ $\left.\mathrm{Cu}^{\mathrm{II}}\right](\mathbf{C})$ and arylboronic acid (2) proceeds to yield $\mathrm{Ar}^{3}-\mathrm{Cu}(\mathrm{II})$ (D) (step i). Following coordination of $\mathrm{NH}$-sulfoximine (1) and deprotonation to form $\mathbf{E}$ (step $\mathrm{ii}$ ), $\mathbf{E}$ undergoes a disproportionation to produce $\mathrm{Cu}$ (III) species $\mathbf{F}$ and a $\mathrm{Cu}(\mathrm{I})$ species (step iii) in a fashion similar to that proposed by the groups of Watson ${ }^{31,32}$ and Stahl ${ }^{33,50}$. Intermediate $\mathbf{F}$ undergoes reductive elimination (step $i v$ ) to generate product 3 and another equiv. of $\mathrm{Cu}(\mathrm{I})$. The stoichiometric reaction converts $\mathrm{Cu}(\mathrm{II})$ to $\mathrm{Cu}(\mathrm{I})$ and forms a small amount of 3. A traditional Chan-Lam coupling would involve oxidation of $\mathrm{Cu}(\mathrm{I}) \mathbf{G}$ back to $\mathrm{Cu}(\mathrm{II}) \mathbf{C}$ (step $v$ ), but our reaction does not employ added oxidant. The reaction next enters the dormant phase, only slowly generating product 3 .

The next phase of the reaction is the photo- and auto-catalytic phase, which has no precedent in the literature. As supported by Stern-Volmer experiments, the $\mathrm{Cu}(\mathrm{I})$ complex of the $\mathrm{NH}$ sulfoximine, $\left[\mathrm{Cu}^{\mathrm{I}}(\mathbf{1})_{2}\right]^{+}\left(\mathbf{C}^{\prime}\right)$, is not a photocatalyst. The $\mathrm{N}-\mathrm{Ph}$ sulfoximine (3)-ligated $\mathrm{Cu}(\mathrm{I})$ complex, $\left[\mathrm{Cu}^{\mathrm{I}}(\mathbf{3})_{2}\right]^{+}\left(\mathbf{D}^{\prime}\right)$ can be quenched by $\mathbf{1}$ and is a potential photocatalyst. Interestingly, calculations indicate that $\left[\mathrm{Cu}^{\mathrm{I}}(\mathbf{3})_{2}\right]^{+}\left(\mathbf{D}^{\prime}\right)$ possesses the highest energy (13.9 kcal/mol) among C', D', and E' (Supplementary Fig. 8), which indicates it is the least stable $\mathrm{Cu}(\mathrm{I})$ species, and therefore, is less likely to serve as the actual photocatalyst in the transformation. In contrast, mixed species $\left[\mathrm{Cu}^{\mathrm{I}}(\mathbf{1})(\mathbf{3})\right]^{+}\left(\mathbf{E}^{\prime}\right)(4.4$ $\mathrm{kcal} / \mathrm{mol}$, Supplementary Fig. 8), which can be generated from $\mathbf{C}^{\prime}$ or D' via a ligand exchange process at room temperature, is believed to facilitate the following photocatalytic process. The catalytic photoredox Chan-Lam coupling cycle is proposed to commence with the excitement of $\mathbf{E}^{\prime}$ by ambient light (step $i^{\prime}$ ) to afford $\left[\mathrm{Cu}^{\mathrm{I}}(\mathbf{1})(\mathbf{3})\right]^{+*}\left(\mathbf{F}^{\prime}\right)$, followed by metal-to-ligand charge transfer (MLCT, step $\left.i i^{\prime}\right)$ to yield $\left[\mathrm{Cu}^{\mathrm{II}}(\mathbf{1})(\mathbf{3})\right]^{+}\left(\mathbf{F}^{\prime}\right)$, featuring a radical anion $\mathrm{NH}$-sulfoximine ligand. Meanwhile, the solvent EtOH coordinates to the $\mathrm{Cu}$ center to afford $\mathrm{G}^{\prime}$. $\mathrm{Cu}$ (II)-facilitated homolysis of $\mathrm{O}-\mathrm{H}$ bond of EtOH occurs to give a formal $\mathrm{Cu}$ (III) species $\mathbf{H}^{\prime}$ (step iii') ${ }^{51}$. The concomitant hydrogen radical, either free or coordinated by ethoxide, attacks the hydrogen in $\mathrm{NH}$ sulfoximine ligand of $\mathbf{H}^{\prime}$ to release dihydrogen gas, and generate a formal $\mathrm{Cu}(\mathrm{III})$ species I' simultaneously (step iv'). Transmetallation of $\mathrm{Ar}^{3}-\mathrm{B}(\mathrm{OH})_{2}$ (2) (step $v^{\prime}$ ) with copper(III) (I') produces the $\mathrm{Cu}^{\mathrm{III}}-\mathrm{Ar}^{3}$ complex (J'), that undergoes reductive elimination $(\mathrm{RE})^{51}$ and ligand exchange (step vi') with $\mathbf{1}$ to generate 3 and close the catalytic cycle. The generated $N$-aryl sulfoximine (3) can bind copper(I), increasing the amount of active copper catalyst and giving rise to autocatalysis. The existence of hydrogen radicals was supported by the generation of TEMPO-H (Fig. 2b) and the spin trapped product (Fig. 2c). Consistent with the proposed mechanism, hydrogen gas was detected in the reaction headspace by GC (Supplementary Fig. 3). 


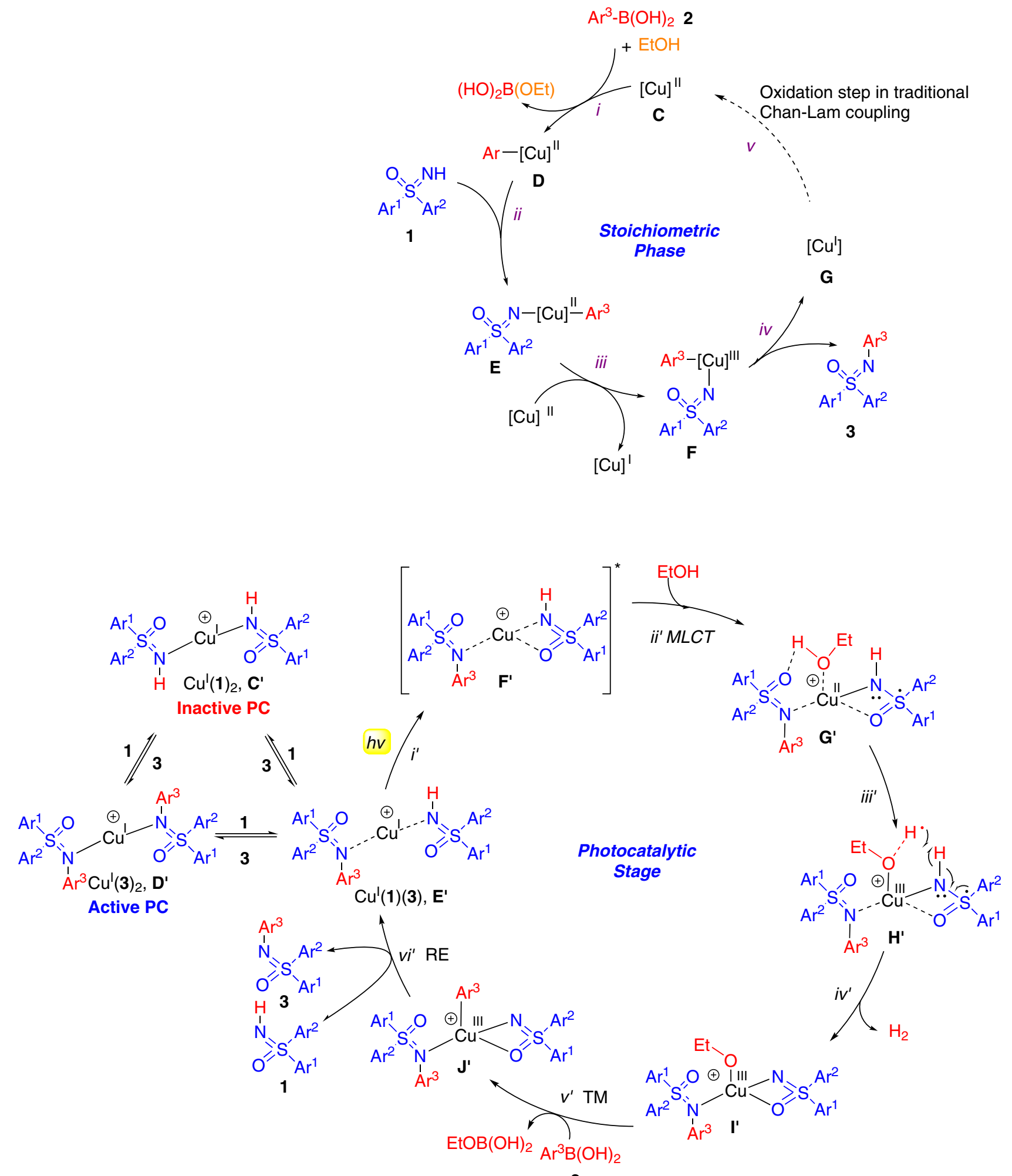

2

Fig. 5 Proposed mechanism of copper-catalyzed photoredox Chan-Lam coupling. The reaction was initiated by a stoichiometric classical oxidative ChanLam coupling, and then entered the photocatalytic stage after $\mathrm{N}$-arylted product $\mathbf{3}$ and $\mathrm{NH}$-sulfoximine $\mathbf{1}$ binding to $\mathrm{Cu}(\mathrm{I})$ together to form the active photocatalyst $\mathbf{E}^{\prime}$.

Computational studies. To understand the nature of the photocatalyst and how hydrogen gas forms, a density-functional theory study of the transformation was initiated (see Supplementary Data 1 for details). According to the proposed mechanism (Fig. 5), the photocatalyst formed in the stoichiometric phase undergoes a MLCT after exposure to light. Alcohol can coordinate to the copper and together with the sulfoximine loses a hydrogen atom to form hydrogen gas. The rest of the cycle is well-precedented for Chan-Lam couplings. The thermodynamics and pathways of key steps were calculated with 


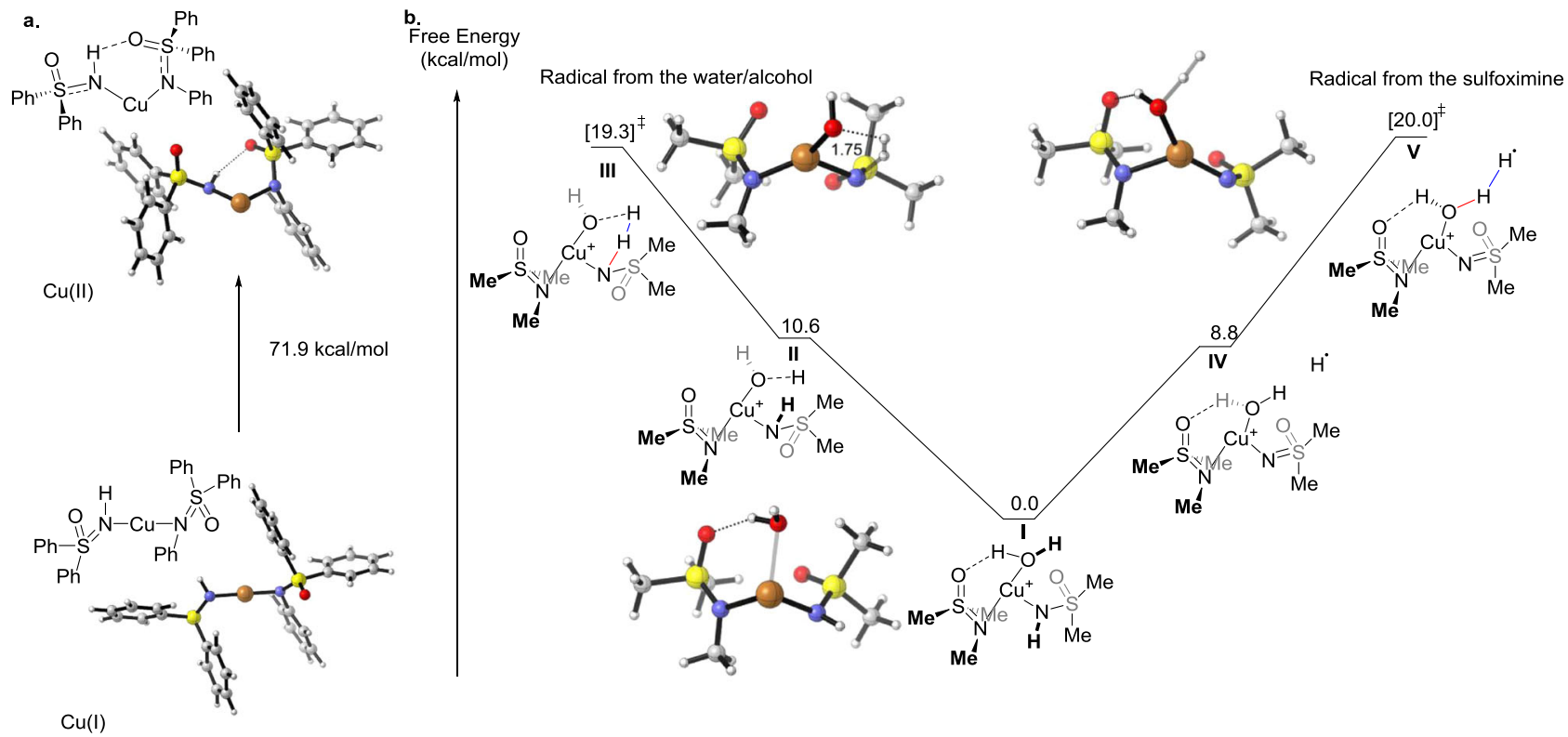

Fig. 6 Computed pathways. a Structures and energy difference of copper(I) and copper(II) photocatalysts. b Energy profiles for the formation of hydrogen gas through radical mechanisms. Free energies computed using B3LYP/6-31 G(d), Cu:SDD.

B3LYP/6-31 G(d), Cu:SDD ${ }^{52-54}$ using Gaussian $16^{55}$, and graphics were made in Cylview ${ }^{56}$.

For both the copper (I) and copper (II) species, the most stable species had two molecules of substrate $\mathbf{1}$ coordinated and the least stable species had two molecules of the product 3 coordinated (Supplementary Fig. 8). In general, the substrate coordinated species were stabilized by hydrogen bonding between the $\mathrm{NH}$ of one sulfoximine and the $\mathrm{S}=\mathrm{O}$ of another. The lesser stability of the 2:1 product: $\mathrm{Cu}$ adducts indicates that product exchange would be favorable consistent with turnover occurring. Although, not isolated in preparations, the 1:1:1 substrate: product: $\mathrm{Cu}$ complexes were found to be of intermediate stability and would be accessible under the reaction conditions (Supplementary Fig. 8). These complexes were stabilized by similar hydrogen bonds as found in the substrate adducts. It appears likely that the 1:1:1 substrate: product: $\mathrm{Cu}$ complex is the active catalyst, but it is unclear if it forms before or after photoexcitation and MLCT. However, the energy needed to excite the copper(I) heterocomplex was lower than either of the homo-complexes (Supplementary Fig. 8 and 6a) and corresponds to light around $400 \mathrm{~nm}$. For these reasons, this mixed species was chosen as a starting point for the pathway calculations.

For the computational analysis of the different pathways, methyl groups were used in place of aryl groups and water was used in place of ethanol in order to reduce computation times. Three different mechanisms for the formation of hydrogen gas were considered: (1) a copper hydride species, (2) $\mathrm{H} \bullet$ arising from the alcohol, and (3) $\mathrm{H}$ • arising from the sulfoximine. The copper hydride pathway has a barrier of $27.6 \mathrm{kcal} / \mathrm{mol}$ to forming the copper hydride from the starting sulfoximine (Supplementary Fig. 9) which is inconsistent with reaction at room temperature. Experimental results described above also indicate that TEMPO inhibits the reaction, which is further inconsistent with a copper hydride pathway ${ }^{57}$.

Examination of the $\mathrm{H}$ - pathways revealed two possibilities (Fig. 6b). The mechanism on the left $(\mathbf{I} \rightarrow \mathbf{I I} \rightarrow \mathbf{I I I})$ forms hydrogen gas through a $\mathrm{H} \bullet$ from the water. The hydrogen dissociates from the water to form an oxygen-associated $\mathrm{H} \bullet$ in II $(\mathrm{O}-\mathrm{H}$ bond length $=2.1 \AA$ ). This oxygen-associated $\mathrm{H}$ • then abstracts the hydrogen on the nitrogen of the sulfoximine via transition state
III to form hydrogen gas. The mechanism on the right to forms $(\mathbf{I} \rightarrow \mathbf{I V} \rightarrow \mathbf{V})$ forms hydrogen gas through a $\mathrm{H} \bullet$ from the sulfoximine. The $\mathrm{H}$ • first dissociates from the sulfoximine to give IV. This $\mathrm{H} \bullet$ then abstracts a hydrogen from the water via transition state $\mathbf{V}$. Although transition state III is slightly lower in energy than transition state $\mathbf{V}$, both pathways are plausible at room temperature.

In summary, an photoredox copper-catalyzed dehydrogenative Chan-Lam coupling of free diaryl sulfoximines and arylboronic acids has been introduced. An array of functional groups, including heteroarylboronic acids and free heteroaryl sulfoximines are viable. Mechanistic investigations reveal a unique autocatalysis process. The ligation of $\mathrm{N}$-arylated sulfoximines to copper species enables its capability as photocatalyst, which efficiently facilitates the $\mathrm{C}-\mathrm{N}$ coupling process in the absence of external oxidant. Understanding the nature of the autocatalysis raises the possibility to tailor copper catalysts with specific ligands to facilitate photoexcitation. The protocol described herein represents an appealing alternative strategy to the classic oxidative $\mathrm{C}-\mathrm{N}$ coupling process, allowing the expansion of substrate generality as well as the elimination of byproducts from catalyst oxidation. The concept of sacrificial oxidant-free photoredox Chan-Lam coupling provides a basis for the design of systems to allow the formation of $\mathrm{C}-\mathrm{N}$ bonds in other contexts.

\section{Methods}

General procedure for catalysis: to an oven-dried microwave vial equipped with a stir bar was added sulfoximine $1(0.75 \mathrm{mmol}, 1.0$ equiv), boronic acid 2 ( $1.5 \mathrm{mmol}$ 2.0 equiv), $\mathrm{Cu}\left(\mathrm{O}_{2} \mathrm{CCF}_{3}\right)_{2} \cdot \mathrm{H}_{2} \mathrm{O}(21.7 \mathrm{mg}, 0.075 \mathrm{mmol}, 10 \mathrm{~mol} \%)$ under an argon atmosphere in a dry box. The vial was capped with a septum and removed from the dry box. EtOH $(0.5 \mathrm{~mL})$ was added into the reaction vial via syringe, and the reaction solution was stirred at room temperature under argon with ambient light for $48 \mathrm{~h}$. Upon completion of the reaction, the vial was opened to air, and the reaction mixture was passed through a short pad of silica gel. The pad was then rinsed with 100:1 dichloromethane:methanol $(20.0 \mathrm{~mL})$. The solvent was removed under reduced pressure. The residue was purified by flash chromatography to afford the purified product.

\section{Data availability}

Experimental procedure and characterization data of new compounds are available within Supplementary Information. Any further relevant data are available from the authors upon reasonable request. 
Received: 28 July 2020; Accepted: 14 January 2021;

Published online: 10 February 2021

\section{References}

1. Furukawa, N., Takahashi, F., Yoshimura, T. \& Oae, S. Reaction synthesis of sulfoximines with diazomalonate in the presence of $\mathrm{Cu}$-salt. A new synthesis and stereochemistry of optically active oxosulfonium ylids. Tetrahedron Lett. 41, 3833-3836 (1977).

2. Bordwell, F. G., Branca, J. C., Johnson, C. R. \& Vanier, N. R. Acidities of sulfoximines and related oxosulfonium cations. Cyclopropyl effects and structures of $\alpha$-sulfonyl-type carbanions. J. Org. Chem. 45, 3884-3889 (1980).

3. Johnson, C. R. Application of sulfoximine in synthesis. Aldrichimica Acta 18, 1-11 (1985).

4. Reggelin, M. \& Zur, C. Sulfoximines: structures, properties and synthetic applications. Synthesis 1, 1-64 (2000)

5. Bizet, V., Hendriks, C. M. \& Bolm, C. Sulfur imidations: access to sulfimides and sulfoximines. Chem. Soc. Rev. 44, 3378-3390 (2015).

6. Siemeister, G. et al. BAY 1000394, a novel cyclin-dependent kinase inhibitor, with potent antitumor activity in mono- and in combination treatment upon oral application. Mol. Cancer Ther. 11, 2265-2273 (2012).

7. Lucking, U. Sulfoximines: a neglected opportunity in medicinal chemistry. Angew. Chem. Int. Ed. 52, 9399-9408 (2013).

8. Frings, M., Bolm, C., Blum, A. \& Gnamm, C. Sulfoximines from a medicinal chemist's perspective: physicochemical and in vitro parameters relevant for drug discovery. Eur. J. Med. Chem. 126, 225-245 (2017).

9. Zhu, Y. et al. Discovery and characterization of sulfoxaflor, a novel insecticide targeting sap-feeding pests. J. Agric. Food Chem. 59, 2950-2957 (2011).

10. Okamura, H. B. C. Sulfoximines: synthesis and catalytic applications. Chem. Lett. 33, 482-487 (2004).

11. Otocka, S., Kwiatkowska, M., Madalinska, L. \& Kielbasinski, P. Chiral organosulfur ligands/catalysts with a stereogenic sulfur atom: applications in asymmetric synthesis. Chem. Rev. 117, 4147-4181 (2017).

12. Schafer, S. \& Wirth, T. A versatile and highly reactive polyfluorinated hypervalent iodine(III) compound. Angew. Chem. Int. Ed. 49, 2786-2789 (2010).

13. Tota, A. et al. Synthesis of $\mathrm{NH}$-sulfoximines from sulfides by chemoselective one-pot N- and O-transfers. Chem. Commun. 53, 348-351 (2017).

14. Moessner, C. \& Bolm, C. $\mathrm{Cu}(\mathrm{OAc})_{2}$-catalyzed $\mathrm{N}$-arylations of sulfoximines with aryl boronic acids. Org. Lett. 7, 2667-2669 (2005).

15. Hosseinian, A. et al. Transition-metal-catalyzed C-N cross-coupling reactions of $N$-unsubstituted sulfoximines: a review. J. Sulfur Chem. 39, 674-698 (2018).

16. Hande, S. et al. Photoredox mediated C-N cross coupling of sulfoximines with aryl iodides. Tetrahedron Lett. 60, 151100 (2019).

17. Gupta, S., Baranwal, S., Muniyappan, N., Sabiah, S. \& Kandasamy, J. Coppercatalyzed $\mathrm{N}$-arylation of sulfoximines with arylboronic acids under mild conditions. Synthesis 51, 2171-2182 (2019).

18. Bolm, C. \& Hildebrand, J. P. Palladium-catalyzed carbon-nitrogen bond formation: a novel, catalytic approach towards $\mathrm{N}$-arylated sulfoximines. Tetrahedron Lett. 39, 5731-5734 (1998).

19. Vaddula, B., Leazer, J. \& Varma, R. S. Copper-catalyzed ultrasound-expedited $\mathrm{N}$-arylation of sulfoximines using diaryliodonium salts. Adv. Synth. Catal. 354, 986-990 (2012).

20. Yang, Q. et al. Palladium-catalyzed $N$-arylation of sulfoximines with aryl sulfonates. J. Org. Chem. 83, 11369-11376 (2018).

21. Zhu, H. et al. Radical $N$-arylation/alkylation of sulfoximines. Tetrahedron Lett. 57, 2372-2374 (2016).

22. Wimmer, A. \& König, B. Visible-light-mediated photoredox-catalyzed $N$ arylation of $\mathrm{NH}$-sulfoximines with electron-rich arenes. Adv. Synth. Catal. 360, 3277-3285 (2018)

23. Wimmer, A. \& König, B. $\mathrm{N}$-Arylation of $\mathrm{NH}$-sulfoximines via dual nickel photocatalysis. Org. Lett. 21, 2740-2744 (2019).

24. Meier, R. et al. Late-stage sulfoximidation of electron-rich arenes by photoredox catalysis. Synlett 29, 2679-2684 (2018).

25. Bachon, A. K., Steinkamp, A. D. \& Bolm, C. N-Arylated sulfoximines as crosscoupling building blocks. Adv. Synth. Catal. 360, 1088-1093 (2018).

26. Wang, L., Priebbenow, D. L., Dong, W. \& Bolm, C. N-Arylations of sulfoximines with 2-arylpyridines by copper-mediated dual N-H/C-H activation. Org. Lett. 16, 2661-2663 (2014).

27. Gao, B., Li, S., Wu, P., Moses, J. E. \& Sharpless, K. B. SuFEx chemistry of thionyl tetrafluoride (SOF4) with organolithium nucleophiles: synthesis of sulfonimidoyl fluorides, sulfoximines, sulfonimidamides, and sulfonimidates. Angew. Chem. Int. Ed. 57, 1939-1943 (2018).

28. Chan, D. M. T., Monaco, K. L., Wang, R. P. \& Winters, M. P. New N- and Oarylations with phenylboronic acids and cupric acetate ${ }^{1}$. Tetrahedron Lett. 39, 2933-2936 (1998).
29. Lam, P. Y. S. et al. New aryl/heteroaryl C-N bond cross-coupling reactions via arylboronic acid/cupric acetate arylation. Tetrahedron Lett. 39, 2941-2944 (1998).

30. West, M. J., Fyfe, J. W. B., Vantourout, J. C. \& Watson, A. J. B. Mechanistic development and recent applications of the Chan-Lam amination. Chem. Rev. 119, 12491-12523 (2019).

31. Vantourout, J. C. et al. Spectroscopic studies of the Chan-Lam amination: a mechanism-inspired solution to boronic ester reactivity. J. Am. Chem. Soc. 139, 4769-4779 (2017).

32. Vantourout, J. C. et al. Mechanistic insight enables practical, scalable, room temperature Chan-Lam $\mathrm{N}$-arylation of $\mathrm{N}$-aryl sulfonamides. ACS Catal. 8, 9560-9566 (2018).

33. King, A. E., Brunold, T. C. \& Stahl, S. S. Mechanistic study of copper-catalyzed aerobic oxidative coupling of arylboronic esters and methanol: insights into an organometallic oxidase reaction. J. Am. Chem. Soc. 131, 5044-5045 (2009).

34. Creutz, S. E. et al. coupling: demonstrating the viability of a radical pathway. Science 338, 647-651 (2012).

35. Ziegler, D. T. et al. A versatile approach to Ullmann C-N couplings at room temperature: new families of nucleophiles and electrophiles for photoinduced, copper-catalyzed processes. J. Am. Chem. Soc. 135, 13107-13112 (2013).

36. Bissember, A. C., Lundgren, R. J., Creutz, S. E., Peters, J. C. \& Fu, G. C Transition-metal-catalyzed alkylations of amines with alkyl halides: photoinduced, copper-catalyzed couplings of carbazoles. Angew. Chem. Int. Ed. 52, 5129-5133 (2013).

37. Kainz, Q. M. et al. Asymmetric copper-catalyzed C-N cross-couplings induced by visible light. Science 351, 681-684 (2016).

38. Zhao, W., Wurz, R. P., Peters, J. C. \& Fu, G. C. Photoinduced, coppercatalyzed decarboxylative $\mathrm{C}-\mathrm{N}$ coupling to generate protected amines: an alternative to the curtius rearrangement. J. Am. Chem. Soc. 139, 12153-12156 (2017).

39. Ahn, J. M., Ratani, T. S., Hannoun, K. I., Fu, G. C. \& Peters, J. C. Photoinduced, copper-catalyzed alkylation of amines: a mechanistic study of the cross-coupling of carbazole with alkyl bromides. J. Am. Chem. Soc. 139, 12716-12723 (2017).

40. Yoo, W. J., Tsukamoto, T. \& Kobayashi, S. Visible-light-mediated Chan-Lam coupling reactions of aryl boronic acids and aniline derivatives. Angew. Chem. Int. Ed. 54, 6587-6590 (2015).

41. Huang, Y., Wen, Q., Jiang, J. H., Shen, G. L. \& Yu, R. Q. A novel electrochemical immunosensor based on hydrogen evolution inhibition by enzymatic copper deposition on platinum nanoparticle-modified electrode. $J$. Biosens. Bioelectron. 24, 600-605 (2008).

42. Koca, A. Copper phthalocyanine complex as electrocatalyst for hydrogen evolution reaction. Electrochem. Commun. 11, 838-841 (2009).

43. Cao, J. P., Fang, T., Fu, L. Z., Zhou, L. L. \& Zhan, S. Z. First mononuclear copper(II) electro-catalyst for catalyzing hydrogen evolution from acetic acid and water. Int. J. Hydrog. Energy 39, 13972-13978 (2014).

44. Zhao, J. et al. Achieving high electrocatalytic efficiency on copper: a low-cost alternative to platinum for hydrogen generation in water. ACS Catal. 5, $4115-4120$ (2015)

45. Dong, X. Y. et al. A crystalline copper(II) coordination polymer for the efficient visible-light-driven generation of hydrogen. Angew. Chem. Int. Ed. 55, 2073-2077 (2016).

46. Bissette, A. J. \& Fletcher, S. P. Mechanisms of autocatalysis. Angew. Chem. Int Ed. 52, 12800-12826 (2013)

47. Blackmond, D. G. Autocatalytic models for the origin of biological homochirality. Chem. Rev. 120, 4831-4847 (2020).

48. Tortora, C. et al. Speeding up viedma deracemization through water-catalyzed and reactant self-catalyzed racemization. ChemPhysChem 21, 1775-1787 (2020).

49. Cheng, G. J., Zhong, X. M., Wu, Y. D. \& Zhang, X. Mechanistic understanding of catalysis by combining mass spectrometry and computation. Chem. Commun. 55, 12749-12764 (2019).

50. King, A. E., Ryland, B. L., Brunold, T. C. \& Stahl, S. S. Kinetic and spectroscopic studies of aerobic copper(II)-catalyzed methoxylation of arylboronic esters and insights into aryl transmetalation to copper(II). Organometallics 31, 7948-7957 (2012).

51. DiMucci, I. M. et al. The myth of d(8) copper(III). J. Am. Chem. Soc. 141, 18508-18520 (2019)

52. Becke, A. D. Density-functional thermochemistry. III. The role of exact exchange. J. Chem. Phys. 98, 5648-5652 (1993).

53. Becke, A. D. A new mixing of Hartree-Fock and local density-functional theories. J. Chem. Phys. 98, 1372-1377 (1993).

54. Lee, C., Yang, W. \& Parr, R. G. Development of the Colle-Salvetti correlationenergy formula into a functional of the electron density. Phys. Rev. B 37, 785-789 (1988).

55. Frisch, M. J. et al. Gaussian 16, Revision B.01 (Gaussian, 2016).

56. Legault, C. Y., CYLview 1.0b; (Université de Sherbrooke, 2009) http://www. cylview.org. 
57. Dang, H., Cox, N. \& Lalic, G. Copper-catalyzed reduction of alkyl triflates and iodides: an efficient method for the deoxygenation of primary and secondary alcohols. Angew. Chem. Int. Ed. 53, 752-756 (2014).

\section{Acknowledgements}

T.J. thanks Shenzhen Nobel Prize Scientists Laboratory Project (C17783101), the Science and Technology Innovation Commission of Shenzhen Municipality (JCYJ20180302180256215), and Guangdong Provincial Key Laboratory of Catalysis (2020B121201002) to provide financial support. SUSTech is gratefully acknowledged for providing startup funds to T.J. (Y01216129). We are also very grateful to professor Lele Duan and Dr. Baihua Long (SUSTech) for the assistance of GC, professor Wei Lu and Xiaobao Zhang (SUSTech) for assistance of Stern-Volmer experiments, and Dr. Yang $\mathrm{Yu}$ (SUSTech) for HRMS. P.J.W thanks the US National Science Foundation (CHE1902509) for financial support. M.C.K. thanks the NIH (GM131902) for financial support and XSEDE (TG-CHE120052) for computational support. This paper is dedicated to the 10th anniversary of Department of Chemistry, SUSTech.

\section{Author contributions}

T.J. designed and supervised the project. C.W., H.Z., T.L., and T.M. performed the experiments. M.C.K. directed the computational study. L.A.W. carried out the computational study. P.J.W. suggested mechanistic experiments. H.Z., T.L., and Q.L. analyzed the results. T.J., P.J.W., and M.C.K. wrote the paper. C.W., H.Z., and L.A.W. contributed equally.

\section{Competing interests}

The authors declare no competing interests.

\section{Additional information}

Supplementary information The online version contains supplementary material available at https://doi.org/10.1038/s41467-021-21156-w.

Correspondence and requests for materials should be addressed to M.C.K. or T.J.

Peer review information Nature Communications thanks Gui Lu, Svetlana Tsogoeva and the other, anonymous, reviewer for their contribution to the peer review of this work. Peer reviewer reports are available.

Reprints and permission information is available at http://www.nature.com/reprints

Publisher's note Springer Nature remains neutral with regard to jurisdictional claims in published maps and institutional affiliations.

\section{(c) (1)}

Open Access This article is licensed under a Creative Commons Attribution 4.0 International License, which permits use, sharing, adaptation, distribution and reproduction in any medium or format, as long as you give appropriate credit to the original author(s) and the source, provide a link to the Creative Commons license, and indicate if changes were made. The images or other third party material in this article are included in the article's Creative Commons license, unless indicated otherwise in a credit line to the material. If material is not included in the article's Creative Commons license and your intended use is not permitted by statutory regulation or exceeds the permitted use, you will need to obtain permission directly from the copyright holder. To view a copy of this license, visit http://creativecommons.org/ licenses/by/4.0/.

(C) The Author(s) 2021 